NOTES

\title{
Scanning Tunneling Microscopic Observation of Shape of Iodine Doped Poly( $N$-vinylcarbazole) Deposited on Graphite Surface
}

\author{
Yukihiro OKa and Akira TAKAHASHI \\ Department of Chemistry for Materials, Mie University, \\ Tsu, Mie 514, Japan
}

(Received October 13, 1990) KEY WORDS Poly( $N$-vinylcarbazole) / Graphite / Scanning Tunneling
Microscope / Iodine Doping / Molecular Shape / Adsorption /

The study of polymer adsorption on an interface is of interest because of diverse applications to colloid stability, adhesion, chromatography and reinforcement. In these studies, it is crucially important to know the conformations of polymers. Theories developed in the past two decades have been mostly concerned with the calculation of $\left\langle z^{2}\right\rangle$ and $\left\langle\left|\rho^{2}\right|\right\rangle$ for chains with one end attached to a wall. Here, $z$ measures the end-vector distance orthogonal to the wall, and $\rho$ is the projection of the end vector in the $z=0$ plane of the wall. $^{1-7}$ Because of a higher polymr density near the surface, theories of polymer adsorption for an single isolated chain predict that $\left\langle\left|\rho^{2}\right|\right\rangle^{1 / 2}$ is larger than the root mean square end-to-end distance $\left\langle r^{2}\right\rangle^{1 / 2}$ in free space. Therefore, the adsorbed shape of polymers on a surface is spreaded form. Dickinson has also reached a similar conclusion by his computer simulation of adsorbed shapes of deformable polymers on a surface. ${ }^{8}$

However, experimental techniques such as ellipsometry and hydrodynamic methods developed until now have been mostly concerned with the measurement of the thickness of the adsorbed layer in the plateau region of adsorption isotherm, where many chains intermingle near the surface. Therefore, $\left\langle z^{2}\right\rangle^{1 / 2}$ and $\left\langle\left|\rho^{2}\right|\right\rangle^{1 / 2}$ measurements have been im- possible.

In an attempt to observe adsorbed shape of an isolated polymer chain, we employed here the scanning tunneling microscope, which was invented by Rohrer and Binning. ${ }^{9}$ For imaging a molecule deposited on a surface, there are two problems. First, it is necessary to reduce molecular motion or diffusion on a surface. The second is to give contrast for the molecule. The former problem may be dissolved in the case of polymer adsorption, since number of segments per molecule interact with the substrate is large. ${ }^{1}$ For the latter problem, although the contrast generation is still a matter of debate, we considered that this problem may be dissolved by giving conductivity to polymer chains with addition of doping agent, although recent study showed that poly(ethylene oxide) can be visualized without doping. ${ }^{10}$ However, doping probably brings a sacrifice in observation of molecular structure, but will allow us to observe global shape of deposited polymer on a surface, although succesful STM observations of DNA, proteins and liquid crystals etc. have been reported. ${ }^{12-14}$

As a sample, poly $(N$-vinylcarbazole) $(\mathrm{PVCz})$ was selected and it was purchased from Tokyo Kasei Co. PVCz was dissolved in chloroform, precipitated by addition of acetone, and dried 
in vacuo. The molecular weight of $\mathrm{PVCz}$ was determined from intrinsic viscosity measurement in chloroform at $25^{\circ} \mathrm{C}$ according to the viscosity equation ${ }^{11}$

$$
[\eta]=19.6 \times 10^{-3} M_{w} 0.67
$$

and the molecular weight was $8.1 \times 10^{5}$.

Solutions of $\mathrm{PVCz}$ doped with iodine were prepared as follows. For a specified concentration of chloroform solutions of $\mathrm{PVCz}, \mathrm{I}_{2}$ was added, so that the ratio of $\mathrm{I}_{2}$ to monomer unit of PVCz equals unity.

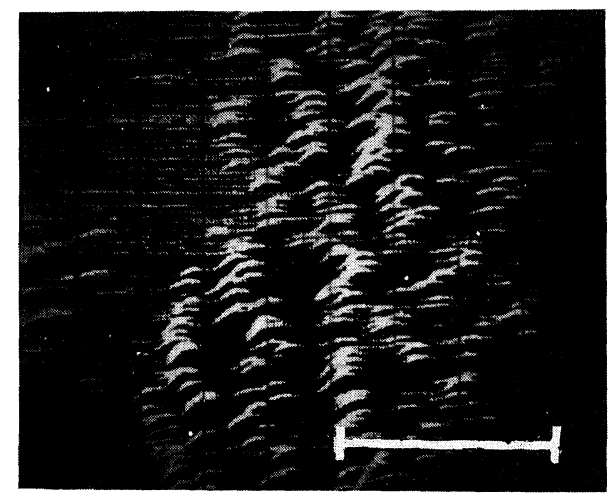

Figure 1. STM image of $\mathrm{I}_{2}$ doped PVCz deposited from $\mathrm{CHCl}_{3}$ solution $\left(C_{\mathrm{p}}=0.35 \mathrm{~g} \mathrm{dl}^{-1}\right)$. The tunneling current, $1.7 \mathrm{nA}$; The bias voltage, $50 \mathrm{mV}$. The line segment corresponds to $100 \mathrm{~nm}$.

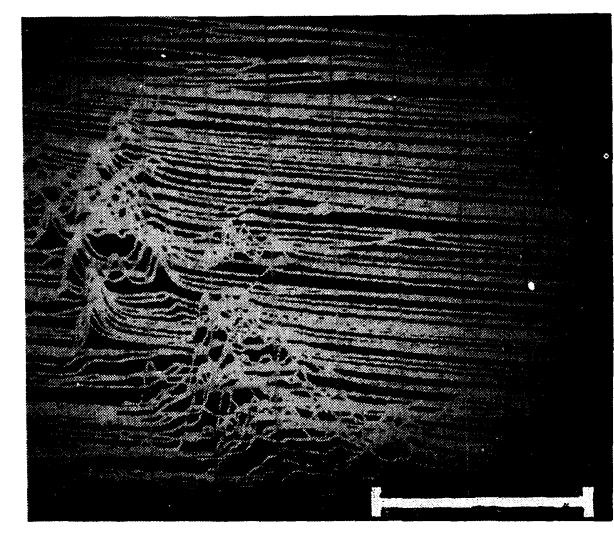

(a)
A droplet of the solution was applied on a freshly cleaved, highly oriented pyrolytic graphite (HOPG, Union Carbide, grade ZYA) substrate and then was allowed to dry at room temperature in a clean box.

STM observation was carried out by Nanoscope I (Digital Instruments, Inc.) at constant current mode. The particular conditions of tunneling were typically $50 \mathrm{mV}$ sample bias and $2 \mathrm{nA}$ tunneling current.

The STM image which was observed for $\mathrm{PVCz}-\mathrm{I}_{2}$ complex deposited from either concentrated $\left(0.35 \mathrm{~g} \mathrm{dl}^{-1}\right)$ or dilute $\left(0.002 \mathrm{~g} \mathrm{dl}^{-1}\right)$ solutions, exhibits bundle like aggregation of molecules whose width is as large as $10 \mathrm{~nm}$ as shown in Figure 1, and observation of isolated polymer chains was unsuccessful. While the STM images of PVCz deposited from the polymer solution whose concentrations are intermediate i.e., $0.023-0.18 \mathrm{~g} \mathrm{dl}^{-1}$ showed different shape as shown in Figure 2, although the reason why this intermediate concentration allowed the observation of these shapes is not clear. Its diameter is about $100 \mathrm{~nm}$ and probably the image corresponds to an isolated polymer chain.

For glass transition temperature of $\mathrm{PVCz}$, rather conflicting values $357,{ }^{15} 423,,^{16}$ and

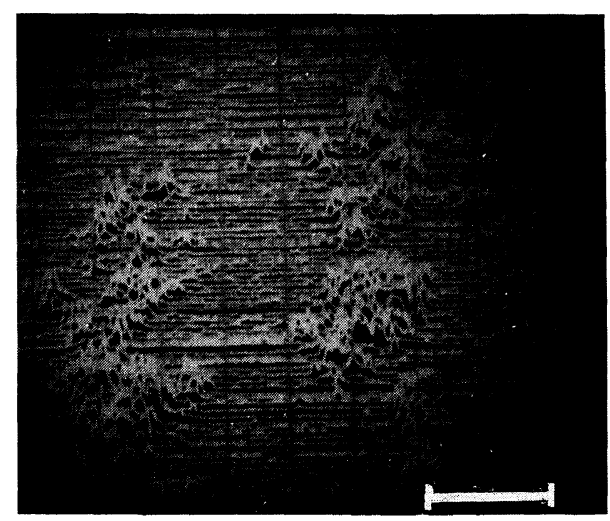

(b)

Figure 2. STM images of $\mathrm{I}_{2}$ doped $\mathrm{PVCz}$ deposited from $\mathrm{CHCl}_{3}$ solutions. The line segment corresponds to $100 \mathrm{~nm}$. (a) $C_{p}=0.18 \mathrm{~g} \mathrm{dl}^{-1}$. Tunneling current $3.5 \mathrm{nA}$ and bias voltage $90 \mathrm{mV}$. (b) $C_{p}=0.023 \mathrm{~g} \mathrm{dl}^{-1}$, $2.0 \mathrm{nA}$ and $30 \mathrm{mV}$. 
$481 \mathrm{~K},{ }^{17}$ respectively, were reported and exact $T_{\mathrm{g}}$ value has not yet been settled. Nevertheless, these values are higher than room temperature $298 \mathrm{~K}$, hence we may suppose that the molecular motion of $\mathrm{PVCz}$ on the graphite surface is hampered. Comparison of the radius $r$ of $\mathrm{PVCz}$ deposited on the graphite surface with the compact radius $R$ of $\mathrm{PVCz}$ in free space was made. $R$ is given by $R=(3 M)$ $\left.4 \pi \mathrm{d} N_{\mathrm{A}}\right)^{1 / 3}$, where $M$ is the molecular weight, $d$ is the density of $\mathrm{PVCz}$, respectively and $N_{\mathrm{A}}$ is Avogradro number. Taking $\mathrm{d}=1.2$ $\mathrm{g} \mathrm{cm}^{-3},{ }^{18}$ we obtain $R=14 \mathrm{~nm}$, which is considerably smaller than the radius of the PVCz images $50 \mathrm{~nm}$.

de Gennes ${ }^{19}$ has pointed out that when the glass transition temperature of bulk polymers is higher than room temperature, the first few adsorbed layers near the wall may become glassy. Then we expect the freezing of motion of monomer units which were directly attached to the surface and the occupied area of $\mathrm{PVCz}$ adsorbed from solution does not change even in the process of evaporation of solvent. Although we could not evaluate $\left\langle\left|\rho^{2}\right|\right\rangle^{1 / 2}$ for $\mathrm{PVCz}$, however, since we may consider that probably the diameter $D$ of $\mathrm{PVCz}$ images and $\left\langle\left|\rho^{2}\right|\right\rangle^{1 / 2}$ do not differ appreciably, we may also expect the diameter $D$ will be slightly larger than the root mean square end to end distance of $\mathrm{PVCz}$ in solution. In order to test this hypothesis, comparison of the observed diameter $D$ of $\mathrm{PVCz}$ images and the root mean square end to end distance of $\mathrm{PVCz}$ with and without $\mathrm{I}_{2}$ dopping is made. The root mean square end-to-distance $\left\langle r^{2}\right\rangle^{1 / 2}$ were estimated from intrinsic viscosity measurements of $\mathrm{PVCz}$ in chloroform as well as the iodine added chloroform solution by using Flory-Fox equation and the results were shown in Table I. The larger $\left\langle r^{2}\right\rangle^{1 / 2}$ for $\mathrm{PVCz}-\mathrm{I}_{2}$ complex probably originates from excluded volume effect of the complex or charge effect. The comparison of the diameter $D(100 \mathrm{~nm})$ and $\left\langle r^{2}\right\rangle^{1 / 2}(81 \mathrm{~nm})$ indicates that $D$ is slightly larger than the mean square end-to-end
Table I.

\begin{tabular}{|c|c|c|}
\hline$[\eta]$ & $\left\langle r^{2}\right\rangle^{1 / 2}$ & $\begin{array}{c}\text { Concentration } \\
\text { of iodine }\end{array}$ \\
\hline $\mathrm{dlg}^{-1}$ & $\mathrm{~nm}$ & $\mathrm{~g} \mathrm{dl}^{-1}$ \\
\hline 1.24 & 78.6 & 0 \\
\hline 1.42 & 81.2 & 0.030 \\
\hline
\end{tabular}

distance as is expected.

Since the height of deposited polymer chain could not been measured at present stage, what we can say at most from the observed diameter is that collapse of adsorbed chains probably happened. The most serious obstacle for imaging of deposited polymer on graphite surface is low success rate of observation, which in turn prevents statistical average calculation of sizes.

In conclusion, although we could not observe the detailed polymer structure of $\mathrm{PVCz}_{-}$ $\mathrm{I}_{2}$ complex deposited on graphite, we could observe slightly collapsed global shape of deposited $\mathrm{PVCz}-\mathrm{I}_{2}$ complex when compared with the shape of a random coil in free space.

Acknowledgment. This work was supported by a Grant-in-Aid for Scientific Research (No. 63470089) the Ministry of Education, Science, and Culture of Japan.

\section{REFERENCES}

1. A Takahashi and M. Kawaguchi, Adv. Polym. Sci., 46, 1 (1982).

2. E. Eisenriegler, K. Kremer, and K. Binder, J. Chem. Phys., 77, 6298 (1982).

3. K. F. Freed, J. Chem. Phys., 79, 3121 (1983).

4. E. Eisenriegler, J. Chem. Phys., 79, 1052 (1983).

5. E. Eisenriegler, J. Chem. Phys., 81, 4666 (1984).

6. A. M. Nemirovsky and K. F. Freed, J. Chem. Phys., 83, 4166 (1985).

7. J. F. Douglas, A. M. Nemirovsky, and K. F. Freed, Macromolecules, 19, 2041 (1986).

8. E. Dickinson and S. R. Euston, J. Chem. Soc., Faraday Trans., 86, 805 (1990).

9. G. Binning, H. Rohrer, Ch. Gerber, and E. Weibel, Phys. Rev. Lett., 49, 57 (1982).

10. R. Yang, X. R. Yang, D. F. Evans, W. A. 
Hendrickson, and J. Baker, J. Phys. Chem., 94, 6123 (1990).

11. G. Sitaramaiah and D. Jacobs, Polymer, 11, 165 (1970).

12. T. P. Beebe Jr., T. E. Wilson, D. F. Ogletree, J. E. Katz, R. Balhorn, M. B. Salmeron, and W. J. Siekhaus, Science, 243, 370 (1989).

13. R. D. Edstrom, M. H. Meinke, X. R. Yang, R. Yang, and D. F. Evans, Biochemistry, 28, 939 (1989).

14. D. P. E. Smith, J. K. H. Horber, G. Binning, and H. Nejoh, Nature, 344, 641 (1990).

15. A. H. Willbourn, Trans. Faraday. Soc., 54, 717
(1958).

16. E. Jenckel, Kolloid Z., 100, 163 (1942).

17. F. Wuerstlin, in "Die Physik der Hochpolymeren," ed. H. A. Stuart, Springer-Verlag, Berlin, 1959, Chapter 11.

18. R. A. Pethrick, Ed., "Polymer Yearbook," Vol. 2, Horwood, London, 1985, p 100.

19. P. G. de Gennes, in "Molecular Conformation and Dynamics of Macromolecules in Condensed Systems," M. Nagasawa, Ed., Elsevier, Amsterdam, 1988 , p 315. 